pendent on IL-3 for survival ${ }^{3}$. What is the nature of the receptors expressed by $\mathrm{pDC}_{2}$ that are involved in the interaction with different viruses, and what is the role of ILT3, which may inhibit DC functions? What are the effects mediated by virus on $\mathrm{pDC}_{2}$ function, differentiation and maturation? Can, for example, persistent viruses like CMV or HIV escape immune surveillance by subverting $\mathrm{pDC}_{2}$ function and/or maturation? Do $\mathrm{pDC}_{2}$ secrete any other principal cytokines? And finally, what is the function of $\mathrm{pDC}_{2}$ in the context of tumor immunity? Do tumor cells block IFN- $\alpha$ release by $\mathrm{pDC}_{2}$ to escape immune surveillance, or could the type 2 T-helper cell responses induced by mature $\mathrm{DC}_{2}$ be favoring tumor growth? Finding answers to all these questions will open new exciting research avenues that will increase our understanding of the development and maintenance of protective immunity.

1. Hoffmann, J.A., Kafatos, F.C., Janeway, C.A. \& Ezekowitz, R.A. Phylogenetic perspectives in innate immunity. Science 284, 1313-1318 (1999)

2. Banchereau, J. \& Steinman, R.M. Dendritic cells and the control of immunity. Nature 392, 245-252 (1998).

3. Grouard, G. et al. The enigmatic plasmacytoid T cells develop into dendritic cells with interleukin (IL)-3 and CD40-ligand. J Exp Med 185, 1101-1111 (1997).

4. Olweus, J. et al. Dendritic cell ontogeny: a human dendritic cell lineage of myeloid origin. Proc. Natl. Acad. Sci. USA 94, 12551-12556 (1997).

5. Cella, M. et al. Plasmacytoid monocytes migrate to inflamed lymph nodes and produce high levels of type I IFN. Nature Med. 5, 919-923 (1999).

6. Siegal, F.P. et al. The nature of the principal type 1 interferon-producing cells in human blood. Science 284, 1835-1837 (1999)

7. Meager, A.in Cytokines (eds. Mire-Sluis, A.R. \& Thorpe, R.) 361-380 (Academic, New York, 1998).

8. Fitzgerald-Bocarsly, P., Feldman, M., Mendelsohn M., Curl, S. \& Lopez, C. Human mononuclear cells which produce interferon-alpha during NK(HSV- FS) assays are HLA-DR positive cells distinct from cytolytic natural killer effectors. J. Leukoc. Biol. 43, 323-334 (1988).

9. Sandberg, K., Gobl, A.E., Funa, K. \& Alm, G.V. Characterization of the blood mononuclear leucocytes producing alpha interferon after stimulation with herpes simplex virus in vitro, by means of combined immunohistochemical staining and in situ RNA-RNA hybridization. Scand. J. Immunol. 29, 651-658 (1989).

10. Muller-Hermelink, H., Stein, H., Steinman, G. \& Lennert, K. Malignant lymphoma of plasmacytoid T cells. Morphologic and immunologic studies char- acterizing a special type of T cell. Am. J. Surg. Pathol. 8, 849-862 (1983).

11. Facchetti, F., De Wolf-Peeters, C., van den Oord, J., De vos, R. \& Desmet, V. Plasmacytoid T cells: a cell population normally present in the reactive lymph node. An immunohistochemical and electronmicroscopic study. Hum. Pathol. 19, 1085-1092 (1988).

12. Rissoan, M.C. et al. Reciprocal control of T helper cell and dendritic cell differentiation. Science $\mathbf{2 8 3}$, 1183-1186 (1999)

13. Payvandi, F., Amrute, S. \& Fitzgerald-Bocarsly, P. Exogenous and endogenous IL-10 regulate IFN-a production by peripheral blood mononuclear cells in response to viral stimulation. J. Immunol. 160, 5861-5868 (1998).

14. Vallin, H., Blomberg, S., Alm, G., Cederblad, B. \& Ronnblom, L. Patients with systemic lupus erythematosus (SLE) have a circulating inducer of interferon-alpha (IFN-alpha) production acting on leucocytes resembling immature dendritic cells. Clin. Exp. Immunol. 115, 196-202 (1999).

15. Bruno, L., Res, P., Dessing, M., Cella, M. \& Spits, H. Identification of a committed T cell precursor population in adult human peripheral blood. J. Exp. Med. 185, 875-884 (1997).

Baylor Institute for Immunology Research

3434 Live Oak

Dallas, Texas 75204 USA

Fax: 2148204813

j.banchereau@baylordallas.edu

\section{Downless is a tumor necrosis factor-like receptor}

First described by Darwin in 1875 as a condition affecting the 'toothless men of Sind'-members of a Hindu kindred from the Hyderabad region of India-hypohidrotic ectodermal dysplasia (HED) is characterized by abnormal development of the teeth, hair and sweat glands.

Three mouse lines, Tabby ( $T a)$, Crinkled ( $c r$ ) and Downless $(d l)$, show the same phenotype as HED, and Overbeek and colleagues have now cloned the $d l$ gene using a classic positional cloning approach, as described in the August issue of Nature Genetics.

They report that the $d l$ expression pattern changes from being uniform in the basal cells of the epidermis to being restricted to placodes during follicular morphogenesis.

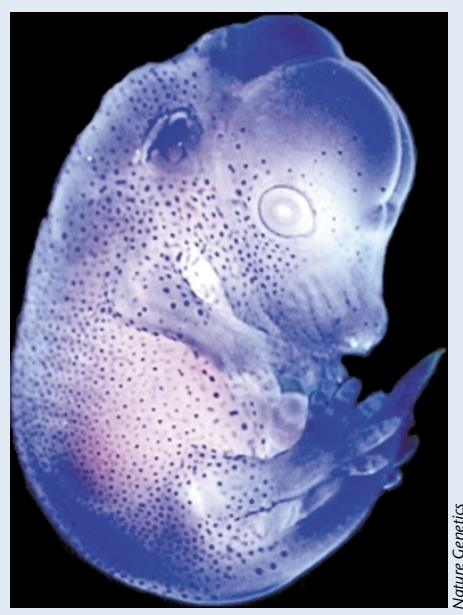

The figure shows in situ hybridization of $d l$ on an Ove951 mouse embryo at day 15 . Epidermal placodes begin to form on the trunk by day 14, and distinct waves of new follicle formation occur until a few days after birth. Placodes are clearly visible as scattered, regularly spaced dots. The low level of expression in the surrounding cells suggests that a complex form of inductive and inhibitory signals is responsible for epithelial patterning.

Based on sequence similarities, the protein encoded at the $d$ llocus is thought to encode a tumor necrosis factor-like transmembrane receptor. In fact, Tabby CDNA has been cloned recently, and sequence analysis shows it has homology to the tumor necrosis factor family, indicating that the product of $T a$ could be a $d /$ ligand. Moreover the human homolog of $T a$ has been found mutated in the X-linked form of HED. A new signaling pathway responsible for cell induction and hair follicle cell fate seems to emerge.

In the same issue of Nature Genetics, Monreal et al. report the identification of $d$ l human homolog mutations in three HED families. So now the race is on to clone Crinkled.

Beatrice Renault

\section{Amyloid- $\beta$ vaccine for Alzheimer Disease}

Amyloid beta $(A \beta)$ peptide, a 40-42 amino acid protein cleaved from the amyloid precursor protein (APP), is a main constituent of the amyloid plaques found in the brains of Alzheimer Disease (AD) patients. Much debate has revolved around the question of whether $A \beta$ is part of the biochemical process that causes the loss of function associated with $A D$ or whether it is simply a by-product of the disease pathology.

In the July 8 issue of Nature, Shenk et al. report new a tool that may be useful in answering this critical question. They describe the immunization with $A \beta_{42}$ of PDAPP mice (a transgenic strain that overexpresses the mutant human APP) and show that this "AD vaccine" prevents and even reverses $A \beta$ plaque formation and other typical AD-like neuropathologies.

In an accompanying News and Views, Peter St. George-Hyslop points out that this mouse vaccine system can now be used to test whether depletion of amyloid plaques is accompanied by a reduction in the behavioral and neurophysiological symptoms of $A D$. Perhaps of even more interest to many biomedical researchers is the question of whether this $A \beta_{42}$ immunization approach is feasible in humans. Kristine Novak 